\section{Humour should be taken seriously}

Sir - P.-L. Chau and W.Y. Chau ignore some important points in their defence of Confucianism (Nature 385, 110; 1997).

First, Confucianism as actually practised, emphasizing deference towards seniors and elders, has resulted in authoritarianism (as well as such positive virtues as refinement of the person). Second, Confucian-influenced cultures such as China, Korea, Japan and Vietnam were not deeply permeated by Christianity and its concomitant emphasis on the importance of the individual. This distinctive Christian individualism underlies the Weber/Tawney thesis that Christianity gave rise to capitalism. It has also greatly encouraged originality in the West, because the individual who thinks independently of the group or tradition in which he or she lives is usually respected and valued.

Japan has suffered from the same absence of scientific creativity as has Korea. But in China, Taoism, with its emphasis on spontaneity and paradoxes, probably encouraged more original scientific thought, particularly in the fields of electromagnetism and the invention of the compass. Nevertheless, China did not undergo a scientific revolution, as did the West in the sixteenth and seventeenth centuries, probably because it lacked Christian-influenced individualism.

Confucianism does encourage selfdiscipline and is excellent for arduous training techniques. Korea and Japan excel, for example, in the efficient production of players of musical instruments. It could, however, be argued that there are now too many Korean child prodigy violinists in the West. An original and beautiful musical composition from Korea or Japan would surely now be more appreciated.

In a leading article on Confucianism (Nature 384, 197; 1996), you ask "So how to boost scientific creativity?". One important way to do this, hitherto ignored, is by encouraging humour in scientific communities which often think convergently. Humour develops divergent thinking, an important aspect of creativity. Wit can often shift a train of thought to an entirely new mode of perception. Above all, humour usually involves the momentary fusion of two habitually incompatible frames of reference. The sudden comprehension of abrupt incongruity generally results in laughter and the release of tension. It frees the mind from the restraints of logic and rational decision. The resulting relaxed playful atmosphere often encourages further divergent and creative thought.

The precise relationship between creativity and humour has not been given the attention it deserves. In his MSc thesis (University of Surrey, 1995), Vaughan Goddard demonstrated that subjects who watched a videotape of Stephen Hawking's A Brief History of Time before taking a creativity test scored lower than a group of people (with similar backgrounds) who had just watched a humorous videotape (Jack Dee).

Humour should therefore surely be regarded very seriously by all scientists, even including those from non-Confucian cultures.

\section{Audrey Wells}

Department of History,

Royal Holloway,

University of London,

Egham, Surrey TW20 OEX, UK

\section{The ' $s$ ' in Unesco}

Sir - Declan Butler's News article about Unesco (Nature 385, 286; 1997) omits any mention of the major issues that confront any intergovernmental approach to science. As a former assistant director general (science) at Unesco, I should like to make the following comments.

The main issue probably relates to the inextricable relations between science and technology, that is, between free research for new knowledge and jealously patented intellectual property. This leads to diminishing support from governments for basic science. This also explains why developing countries have constantly pressed for a better share of 'science and technology', through, among other things, the UN conference on the subject held in Vienna in 1979, without ever obtaining anything but nice words.

Science itself lies in the minds of scientists and is essentially concentrated in the industrialized world. It has its own traditional channels of communication, particularly through the multiple unions and associations gravitating around the International Council of Scientific Unions. Specialists in brain research, or indeed in physics or chemistry, do not necessarily find much value in cooperating through Unesco, and most of them do not feel much interest in promoting their disciplines in the developing world. But the developing world needs some means of contact and participation in scientific matters if it is actually to develop. Weakened as it may be because of the absence of the United States and the United Kingdom, and because of lack of support from international funding agencies, Unesco is still the only multilateral organization devoted to the promotion of science in the developing world. But obviously it cannot do so without support from the industrialized countries.
These countries are quite happy to use Unesco when it suits their own immediate interest as, for instance, when a world forum is needed in bioethics, or when the nature of the research work to be conducted implies the goodwill and participation of developing countries. This is clearly true when the geographical dimension of the problems is paramount. As you rightly point out, the international scientific programmes of Unesco in hydrology, geology and oceanography are "well respected". To these could be added programmes in microbial resources and in biological diversity, and particularly the Man and the Biosphere Programme, with its world network of 'biosphere reserves'. Although they do not contribute to their overhead costs, the United States and the United Kingdom continue to take part in and to benefit from these global research programmes. This fact alone seems to justify the value of the ' $s$ ' in Unesco.

Some multilateral mechanism is more than ever needed to ensure better access to science on a worldwide basis and to deliver cooperatively the necessary knowledge on global interdisciplinary issues which govern our future on this Earth. Unesco has received this mandate. All those concerned should see to it that it fulfils it well.

Michel Batisse

7 Rue de la Cavalerie,

75015 Paris, France

\section{Science and emotion}

Sir - Few objective scientists would disagree with the view that emotion and passion have a very real place in the world of science. Until fairly recently, however, this idea might have occasioned an outcry from many scientists and would certainly have been unlikely to appear in the editorial columns of Nature $(385,373 ; 1997)$.

But it is largely because of so-called 'science studies' that the myth of the passionless scientist is fast disappearing. Although it may be true that the passions of science "... may often have little impact on what eventually becomes accepted as scientific truth", the process of reaching that goal, as I have attempted to demonstrate in a recent book (Envy as a Retarding Force in Science, Avebury, Aldershot, 1996), may well be slowed and retarded by the human emotions that are often at play in science. Indeed, envy may be one of the important human emotions responsible for the inertia that often delays the acceptance of profoundly important scientific truths.

Mark A. Gillman

South African Brain Research Institute,

6 Campbell Street, Waverley,

2090 Johannesburg, South Africa

e-mail:mag@iafrica.com 